Research Article

\title{
Risk Factors for Brain Metastases in Patients with Renal Cell Carcinoma
}

\author{
Zhi-Bin Ke ${ }^{(D)}$, Shao-Hao Chen (D), Ye-Hui Chen $(\mathbb{D}$, Yu-Peng Wu $(\mathbb{D}$, Fei Lin $(\mathbb{D}$, Xue-Yi Xue $(\mathbb{D}$, \\ Qing-Shui Zheng $\mathbb{D}$, Ning Xu $\mathbb{D}$, and Yong Wei
}

Department of Urology, The First Affiliated Hospital of Fujian Medical University, Fuzhou 350005, China

Correspondence should be addressed to Ning Xu; drxun@fjmu.edu.cn and Yong Wei; weiyong2017@fjmu.edu.cn

Received 13 August 2019; Revised 8 February 2020; Accepted 27 February 2020; Published 9 March 2020

Academic Editor: Vida Demarin

Copyright (c) 2020 Zhi-Bin Ke et al. This is an open access article distributed under the Creative Commons Attribution License, which permits unrestricted use, distribution, and reproduction in any medium, provided the original work is properly cited.

\begin{abstract}
Background. Patients with brain metastases (BM) from renal cell carcinoma (RCC) were considered to experience a poor prognosis. However, there is little knowledge on the risk factors for BM from RCC at diagnosis. This study was aimed at exploring the risk factors for patients with BM from RCC and the interaction among these risk factors. Methods. A total of 38759 cases of RCC were identified from the Surveillance, Epidemiology, and End Results (SEER) database. Risk factors for BM from RCC were evaluated by univariate and multivariate logistic regression analyses. Interaction effect between age and tumor size was tested. Results. There was a significant difference in univariate analysis, including T stage, tumor size, grades III and IV, lymph node metastasis, bone metastasis, liver metastasis, lung metastasis, and surgery. There was a significant difference in multivariate analysis, including age, $\mathrm{T}$ stage, tumor size $<10 \mathrm{~cm}$, grade IV, lymph node metastasis, bone metastasis, lung metastasis, and surgery. Patients older than 70 had 0.653 -fold lower risk of developing BM compared with those younger than 70 . Patients with tumor size $\geq 4 \mathrm{~cm}$ and $<10 \mathrm{~cm}$ had higher risk of developing $\mathrm{BM}$ compared with those $<4 \mathrm{~cm}$. The larger the tumor size, the higher the incidence of BM from RCC in those whose tumor size was less than $10 \mathrm{~cm}$. An interaction test between the tumor size and age on brain metastasis was statistically significant in the crude analysis $(P=0.0114)$ and model II analysis $(P=0.0248)$ but not in model I analysis $(P=0.1136)$. Although age significantly affected the risk of BM from RCC, impact of age on the risk of developing BM from RCC was limited to patients with tumor size $\geq 7 \mathrm{~cm}$. Conclusion. Both tumor size and age were independent risk factors for brain metastases in patients with RCC. The impact of age on the risk of developing BM from RCC was limited to patients with tumor size $\geq 7 \mathrm{~cm}$. Patients with a larger tumor size and younger age might have the higher risk of developing BM at diagnosis of RCC.
\end{abstract}

\section{Introduction}

The incidence of renal cell carcinoma (RCC) has continued to increase recently, most of whom were localized $[1,2]$. However, approximately $30 \%$ of nonmetastatic RCC would progress to metastatic disease after definitive treatment [3]. Nonmetastatic RCC patients developed brain metastases (BM) in $2.4 \%$ of cases [1]. It is estimated that incidence proportions of BM from RCC at diagnosis was $6.5 \%[1,4]$. Patients with BM from RCC were considered to experience a poor prognosis [5]. In the past 20 years, the incidence of BM from RCC was reported to increase significantly $[6,7]$. Understanding the risk factors of developing BM is impor- tant to diagnosis, treatment, prevention, and counseling in patients with BM from RCC. However, there was little study investigating the risk factors of patients with BM from RCC. This study is aimed at determining the risk factors for patients with BM from RCC and testing the interaction among these risk factors.

\section{Methods}

2.1. Data Source. The Surveillance, Epidemiology, and End Results (SEER) database includes information on demographics, cancer incidence, and survival outcomes from population-based registries for approximately $30 \%$ of the 


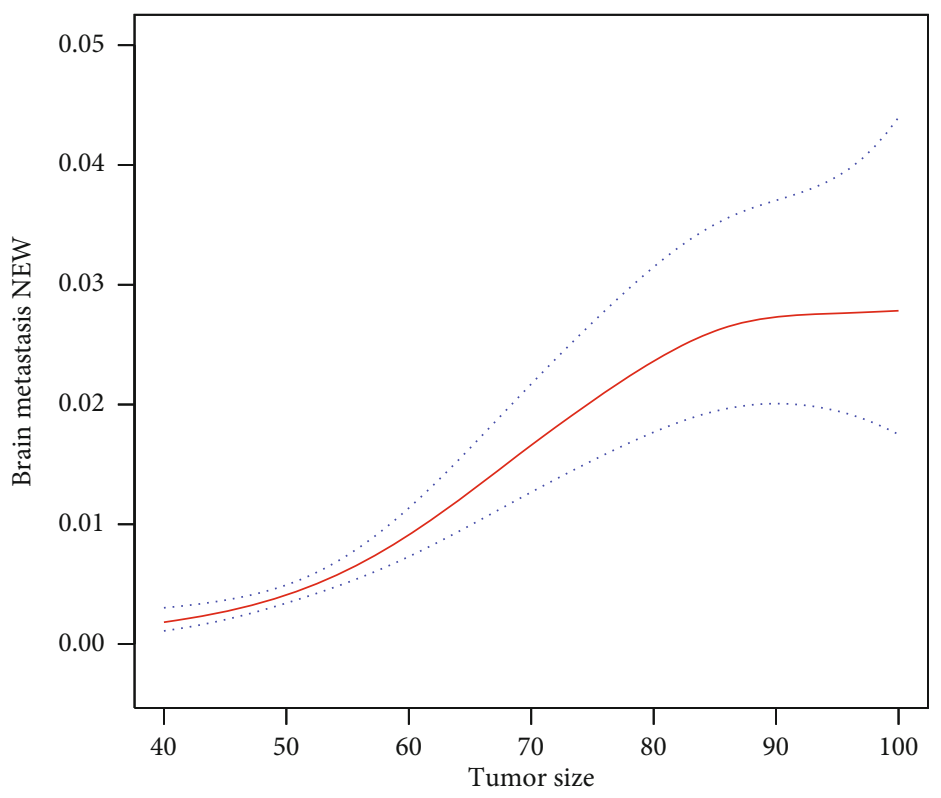

FIGURE 1: Correlation between tumor volume and incidence of brain metastasis in RCC patients with tumor size $<10 \mathrm{~cm}$.

US population. Data of this study were obtained from the SEER program of the National Cancer Institute using the SEER $*$ Stat software (version 8.3.5). Since all information from the SEER database has been deidentified and no personal identifying information was used in this analysis, informed consent is not required for use of the SEER data.

2.2. Statistical Analysis. Statistical analysis was performed using SPSS 21 software. Categorical data were presented as frequency (\%) and analyzed by the chi-squared test or Fisher's test. Continuous data that were normally distributed were represented as mean \pm standard deviation. Univariate and multivariate logistic regression analyses were used to determine risk factors of BM from RCC. $P<0.05$ was considered to be statistically significant. Besides, interactions between age and tumor size were tested.

\section{Results}

We finally included 38759 cases of RCC. Figure 1 reveals that the larger the tumor size, the higher the incidence of brain metastases from RCC in patients whose tumor size was less than $10 \mathrm{~cm}$.

Baseline characteristics of participants are showed in Table 1. The participants were classified into 3 groups by tumor size: tumor size $<7 \mathrm{~cm} \quad(n=28793) ; 7 \mathrm{~cm} \leq$ tumor size $<10 \mathrm{~cm}(n=5804)$; and tumor size $\geq 10 \mathrm{~cm}(n=4162)$. There was a significant difference between these three groups, including tumor size, age, grade, $\mathrm{T}$ stage, $\mathrm{N}$ stage, $\mathrm{M}$ stage, bone metastasis, brain metastasis, liver metastasis, lung metastasis, insurance, Fuhrman grade, surgery, and race, with the exception of marital status. There were significant differences in the incidence of brain metastases among the three groups $(0.205 \%$ vs. $1.568 \%$ vs. $2.427 \%, P<0.001)$.
As showed in Table 2, there was a significant difference in univariate analysis, including $\mathrm{T}$ stage, tumor size, grades III and IV, lymph node metastasis, bone metastasis, liver metastasis, lung metastasis, and surgery. There was a significant difference in multivariate analysis, including age, $\mathrm{T}$ stage, tumor size $<10 \mathrm{~cm}$, grade IV, lymph node metastasis, bone metastasis, lung metastasis, and surgery. Patients older than 70 had 0.653-fold lower risk of developing BM compared with those younger than 70 . Patients with tumor size $\geq 4 \mathrm{~cm}$ and $<7 \mathrm{~cm}$ had 2.270-fold higher risk of developing BM compared with those $<4 \mathrm{~cm}$. Patients with tumor size $\geq 7 \mathrm{~cm}$ and $<10 \mathrm{~cm}$ had 2.360-fold higher risk of developing BM compared with those $<4 \mathrm{~cm}$. It was significantly increased in the risk of $\mathrm{BM}$ for patients whose tumor size was $\geq 4 \mathrm{~cm}$ and $<10 \mathrm{~cm}$ compared with patients with tumors $<4 \mathrm{~cm}$ in diameter. However, while tumor size was $10 \mathrm{~cm}$ or larger, the risk of brain metastasis did not increase significantly compared with patients with tumors $<4 \mathrm{~cm}$ in diameter.

Table 3 further quantifies the effect of tumor size and age on the risk of developing BM at diagnosis of RCC. Model I was adjusted for bone metastasis, liver metastasis, and lung metastasis. Model II was adjusted for grade, $\mathrm{N}$ stage, marital status, race NEW, insurance, and Fuhrman grade. The patients were classified into 6 groups by tumor size and age: group 1 (tumor size $<7 \mathrm{~cm}$ and age $<70$ years), group 2 (tumor size $<7 \mathrm{~cm}$ and age $\geq 70$ years), group 3 $(7 \mathrm{~cm} \leq$ tumor size $<10 \mathrm{~cm}$ and age $<70$ years), group 4 ( $7 \mathrm{~cm} \leq$ tumor size $<10 \mathrm{~cm}$ and age $\geq 70$ years), group 5 (tumor size $\geq 10 \mathrm{~cm}$ and age $<70$ years), and group 6 (tumor size $\geq 10$ $\mathrm{cm}$ and age $\geq 70$ years). There was no significant difference between group 1 and group $2(P>0.05)$; however, the difference between group 1 and other groups was statistically significant $(P<0.05)$. Interaction effect between tumor size and age on the risk of brain metastasis was statistically significant in the crude analysis $(P=0.0114)$ and model II analysis $(P=0.0248)$ but not in model I analysis $(P=0.1136)$. 
TABLE 1: Baseline characteristics classified by primary tumor size of renal cell carcinoma.

\begin{tabular}{|c|c|c|c|c|}
\hline Tumor size & $<7 \mathrm{~cm}$ & $\geq 7 \mathrm{~cm}$ and $<10 \mathrm{~cm}$ & $\geq 10 \mathrm{~cm}$ & $P$ value \\
\hline$N$ & 28793 & 5804 & 4162 & \\
\hline Tumor size & $36.566 \pm 15.200$ & $81.036 \pm 8.339$ & $129.538 \pm 48.279$ & $<0.001$ \\
\hline Age & $59.549 \pm 12.389$ & $61.090 \pm 11.941$ & $59.379 \pm 11.794$ & $<0.001$ \\
\hline Age group & & & & $<0.001$ \\
\hline$<70$ years & $22567(78.377 \%)$ & 4375 (75.379\%) & $3351(80.514 \%)$ & \\
\hline$\geq 70$ years & $6226(21.623 \%)$ & $1429(24.621 \%)$ & $811(19.486 \%)$ & \\
\hline Grade & & & & $<0.001$ \\
\hline Grade I & $3644(12.656 \%)$ & $296(5.100 \%)$ & $128(3.075 \%)$ & \\
\hline Grade II & $16578(57.576 \%)$ & $2256(38.870 \%)$ & $1186(28.496 \%)$ & \\
\hline Grade III & $7573(26.302 \%)$ & $2333(40.196 \%)$ & $1777(42.696 \%)$ & \\
\hline Grade IV & $998(3.466 \%)$ & 919 (15.834\%) & $1071(25.733 \%)$ & \\
\hline $\mathrm{N}$ stage & & & & $<0.001$ \\
\hline N0 & 28485 (98.930\%) & $5424(93.453 \%)$ & 3554 (85.392\%) & \\
\hline N1 & $308(1.070 \%)$ & $380(6.547 \%)$ & $608(14.608 \%)$ & \\
\hline M stage & & & & $<0.001$ \\
\hline M0 & $28141(97.736 \%)$ & $4998(86.113 \%)$ & $3050(73.282 \%)$ & \\
\hline M1 & $652(2.264 \%)$ & $806(13.887 \%)$ & $1112(26.718 \%)$ & \\
\hline Bone metastasis & & & & $<0.001$ \\
\hline No & 28504 (98.996\%) & $5570(95.968 \%)$ & 3879 (93.200\%) & \\
\hline Yes & $289(1.004 \%)$ & $234(4.032 \%)$ & $283(6.800 \%)$ & \\
\hline Brain metastasis & & & & $<0.001$ \\
\hline No & 28734 (99.795\%) & $5713(98.432 \%)$ & 4061 (97.573\%) & \\
\hline Yes & $59(0.205 \%)$ & $91(1.568 \%)$ & $101(2.427 \%)$ & \\
\hline Liver metastasis & & & & $<0.001$ \\
\hline No & 28727 (99.771\%) & $5722(98.587 \%)$ & 3996 (96.012\%) & \\
\hline Yes & $66(0.229 \%)$ & $82(1.413 \%)$ & $166(3.988 \%)$ & \\
\hline Lung metastasis & & & & $<0.001$ \\
\hline No & $28503(98.993 \%)$ & $5301(91.334 \%)$ & 3390 (81.451\%) & \\
\hline Yes & $290(1.007 \%)$ & $503(8.666 \%)$ & $772(18.549 \%)$ & \\
\hline Insurance & & & & $<0.001$ \\
\hline Uninsured & $793(2.754 \%)$ & $197(3.394 \%)$ & $166(3.988 \%)$ & \\
\hline Insured & $27636(95.982 \%)$ & $5547(95.572 \%)$ & $3959(95.123 \%)$ & \\
\hline Unknown & $364(1.264 \%)$ & $60(1.034 \%)$ & $37(0.889 \%)$ & \\
\hline Marital status & & & & 0.095 \\
\hline Unmarried & $9743(33.838 \%)$ & $1943(33.477 \%)$ & $1424(34.214 \%)$ & \\
\hline Married & $17489(60.740 \%)$ & $3586(61.785 \%)$ & $2541(61.052 \%)$ & \\
\hline Unknown & $1561(5.421 \%)$ & $275(4.738 \%)$ & $197(4.733 \%)$ & \\
\hline Fuhrman grade & & & & $<0.001$ \\
\hline I & $3631(12.611 \%)$ & $291(5.014 \%)$ & $126(3.027 \%)$ & \\
\hline II & $16554(57.493 \%)$ & $2255(38.853 \%)$ & $1174(28.208 \%)$ & \\
\hline III & $7558(26.249 \%)$ & $2296(39.559 \%)$ & $1736(41.711 \%)$ & \\
\hline IV & $1050(3.647 \%)$ & $962(16.575 \%)$ & $1126(27.054 \%)$ & \\
\hline Surgery & & & & $<0.001$ \\
\hline No & $420(1.459 \%)$ & $159(2.739 \%)$ & $165(3.964 \%)$ & \\
\hline Partial nephrectomy & $14474(50.269 \%)$ & $425(7.323 \%)$ & $139(3.340 \%)$ & \\
\hline Radical nephrectomy & $13899(48.272 \%)$ & $5220(89.938 \%)$ & $3858(92.696 \%)$ & \\
\hline
\end{tabular}


TABle 1: Continued.

\begin{tabular}{lccc}
\hline Tumor size & $<7 \mathrm{~cm}$ & $\geq 7 \mathrm{~cm}$ and $<10 \mathrm{~cm}$ & $\geq 10 \mathrm{~cm}$ value \\
\hline Race NEW & $277(0.971 \%)$ & $52(0.901 \%)$ & $50(1.210 \%)$ \\
$\quad$ Black & $1641(5.755 \%)$ & $342(5.928 \%)$ & $245(5.929 \%)$ \\
Others & $3510(12.310 \%)$ & $516(8.944 \%)$ & $429(10.382 \%)$ \\
Unknown & $23086(80.964 \%)$ & $4859(84.226 \%)$ & $3408(82.478 \%)$ \\
White & & & $0(0.000 \%)$ \\
T stage NEW & $25420(88.285 \%)$ & $548(9.442 \%)$ & $1570(37.722 \%)$ \\
1 & $0(0.000 \%)$ & $2715(46.778 \%)$ & $2293(55.094 \%)$ \\
2 & $3299(11.458 \%)$ & $2403(41.402 \%)$ & $299(7.184 \%)$ \\
4
\end{tabular}

\section{Discussion}

Patients with RCC were in connection with a significant higher mortality rate once brain metastases occurred [8]. Median survival of these patients varied merely from 4.1 months to 13.4 months [9]. But the risk factors for BM due to RCC were unelucidated fully. This study explored the risk factors for BM from RCC and investigated the interaction effect between age and tumor size on the risk of BM from RCC for the first time.

In this study, there was a significant difference in univariate analysis, including T stage, tumor size, grades III and IV, lymph node metastasis, bone metastasis, liver metastasis, lung metastasis, and surgery. There was a significant difference in multivariate analysis, including age, $\mathrm{T}$ stage, tumor size $<10 \mathrm{~cm}$, grade IV, lymph node metastasis, bone metastasis, lung metastasis, and surgery. These results demonstrated that younger age, higher T stage, tumor size, higher grade, lymph node or bone or lung metastasis, and nonsurgical treatment were risk factors for BM from RCC. Patients with higher $\mathrm{T}$ stage, higher grade, and lymph node or bone or lung metastasis had a higher risk of developing BM from RCC. Besides, the risk of BM was significantly increased in RCC patients without partial/radical nephrectomy, indicating that it is of vital importance for RCC patients to receive surgical treatment of the primary lesion.

This study identified younger age as a risk factor for developing brain metastases, which was also verified in different types of cancer but not in RCC. Ji et al. [10] suggested that age $\leq 60$ years was an independent risk factor for $\mathrm{BM}$ of patients with stage III locally advanced non-small-cell lung cancer. Korkmaz et al. [11] found that it was easier for patients younger than 65 years to develop hippocampal metastasis. Ma et al. [12] identified age $\leq 53$ years as a highrisk factor for developing BM in patients with EGFRmutated advanced lung adenocarcinoma. Warren et al. [13] found that there was a lower probability of BM in inflammatory breast cancer patients with older age at diagnosis. The study conducted by Hung et al. [14] revealed that patients $\leq 35$ years tended to develop cerebral lesions in patients with breast cancer. Maurer et al. [15] showed that age $\leq 40$ years was a risk factor for $\mathrm{BM}$ in patients with HER2-positive breast cancer. Our results demonstrated that younger patients were prone to developing brain metastases, which was similar to previous speculations. Besides, we identified 70 years old as the threshold value. Patients younger than 70 are more likely to develop BM from RCC compared with those older than 70 .

Tumor size influences the risk of developing BM from RCC and other types of tumor, which was demonstrated by previous studies. Schovanek et al. [16] suggested that $4.5 \mathrm{~cm}$ was the optimal cut-off primary tumor size which can predict development of any metastases from pheochromocytoma/paraganglioma. Maurer et al. [15] identified tumor size $>2$ $\mathrm{cm}$ as a risk factor for the development of BM in patients with HER2-positive breast cancer. Sun et al. [7] revealed that white/other race, clear cell histology, sarcomatoid differentiation, T2-4 disease, tumor dimension $>10 \mathrm{~cm}$, and $\mathrm{N}+$ disease were risk factors of BM development at RCC diagnosis. Besides, they constructed a risk model, which included tumor size. In their opinion, patients with tumor size $>10 \mathrm{~cm}$ were more likely to develop BM from RCC, which is inconsistent with our research. This study showed that patients with tumor size $\geq 4 \mathrm{~cm}$ had the higher risk of BM from RCC. There were significant differences in the incidence of brain metastases among the three groups: tumor size $<7 \mathrm{~cm} ; 7 \mathrm{~cm} \leq$ tumor size $<10 \mathrm{~cm}$; and tumor size $\geq 10$ $\mathrm{cm}(0.205 \%$ vs. $1.568 \%$ vs. $2.427 \%, P<0.001)$. Moreover, in those whose tumor size was less than $10 \mathrm{~cm}$, there appeared to be continuously increased risk of BM from RCC with the increase of primary tumor size. However, although the risk of developing BM in patients with tumors size $\geq 10 \mathrm{~cm}$ was higher compared with those $<4 \mathrm{~cm}$, it was not statistically significant.

There was a statistically significant interaction between age and tumor size in the crude analysis $(P=0.0114)$ and model II analysis $(P=0.0248)$, demonstrating that the effect of age on the risk of BM from RCC was affected significantly by tumor size. Although previous studies have identified the effect of tumor size on the risk of BM from RCC, our analysis revealed for the first time that age significantly affected the risk of developing BM from RCC and the impact of age was limited to patients with primary tumor size $\geq 7 \mathrm{~cm}$. Tran et al. [17] have also explored the interaction effect between tumor size and age on the prognosis of patients with papillary thyroid carcinoma and found that the impact of tumor size 
TABLE 2: Univariate and multivariate logistic regression analyses of the risk factors for brain metastasis from renal cell carcinoma.

\begin{tabular}{|c|c|c|}
\hline Exposure & Univariate & Multivariate \\
\hline \multicolumn{3}{|l|}{ Age } \\
\hline$<70$ years & 1 & 1 \\
\hline$\geq 70$ years & $0.802(0.582,1.105), 0.17707$ & $0.653(0.460,0.927), 0.01719$ \\
\hline \multicolumn{3}{|l|}{ T stage NEW } \\
\hline 1 & 1 & 1 \\
\hline 2 & $12.116(8.009,18.329),<0.00001$ & $2.656(1.463,4.823), 0.00133$ \\
\hline 3 & $11.820(8.076,17.300),<0.00001$ & $2.303(1.367,3.881), 0.00173$ \\
\hline 4 & $44.218(26.600,73.505),<0.00001$ & $2.215(1.119,4.384), 0.02245$ \\
\hline \multicolumn{3}{|l|}{ Tumor size } \\
\hline$<4 \mathrm{~cm}$ & 1 & 1 \\
\hline$\geq 4 \mathrm{~cm}$ and $<7 \mathrm{~cm}$ & $5.240(2.780,9.880),<0.00001$ & $2.270(1.154,4.467), 0.01755$ \\
\hline$\geq 7 \mathrm{~cm}$ and $<10 \mathrm{~cm}$ & $21.827(11.950,39.868),<0.00001$ & $2.360(1.128,4.938), 0.02269$ \\
\hline$\geq 10 \mathrm{~cm}$ & $34.081(18.720,62.047),<0.00001$ & $2.070(0.981,4.365), 0.05602$ \\
\hline \multicolumn{3}{|l|}{ Grade } \\
\hline Grade I & 1 & 1 \\
\hline Grade II & $1.342(0.690,2.612), 0.38629$ & $1.350(0.650,2.803), 0.42131$ \\
\hline Grade III & $3.397(1.770,6.520), 0.00024$ & $1.772(0.852,3.684), 0.12578$ \\
\hline Grade IV & $10.877(5.622,21.044),<0.00001$ & $2.462(1.148,5.281), 0.02066$ \\
\hline \multicolumn{3}{|l|}{$\mathrm{N}$ stage } \\
\hline No & 1 & 1 \\
\hline N1 & $7.827(5.738,10.677),<0.00001$ & $0.612(0.423,0.886), 0.00930$ \\
\hline \multicolumn{3}{|l|}{ Bone metastasis } \\
\hline No & 1 & 1 \\
\hline Yes & $23.869(18.107,31.466),<0.00001$ & $3.313(2.397,4.578),<0.00001$ \\
\hline \multicolumn{3}{|l|}{ Liver metastasis } \\
\hline No & 1 & 1 \\
\hline Yes & $13.248(8.498,20.654),<0.00001$ & $0.843(0.505,1.407), 0.51281$ \\
\hline \multicolumn{3}{|l|}{ Lung metastasis } \\
\hline No & 1 & 1 \\
\hline Yes & $50.854(38.975,66.354),<0.00001$ & $10.882(7.745,15.289),<0.00001$ \\
\hline \multicolumn{3}{|l|}{ Marital status } \\
\hline Unmarried & 1 & 1 \\
\hline Married & $1.002(0.770,1.303), 0.98929$ & $1.030(0.771,1.377), 0.84112$ \\
\hline Unknown & $0.517(0.239,1.119), 0.09390$ & $0.878(0.394,1.956), 0.74979$ \\
\hline \multicolumn{3}{|l|}{ Race NEW } \\
\hline Black & 1 & 1 \\
\hline Others & $0.609(0.225,1.651), 0.32989$ & $0.507(0.170,1.516), 0.22427$ \\
\hline Unknown & $0.151(0.050,0.454), 0.00075$ & $0.135(0.040,0.452), 0.00118$ \\
\hline White & $0.526(0.216,1.284), 0.15839$ & $0.429(0.160,1.153), 0.09347$ \\
\hline \multicolumn{3}{|l|}{ Surgery } \\
\hline No & 1 & 1 \\
\hline Partial & $0.004(0.002,0.008),<0.00001$ & $0.042(0.018,0.101),<0.00001$ \\
\hline Radical & $0.058(0.044,0.077),<0.00001$ & $0.132(0.091,0.193),<0.00001$ \\
\hline
\end{tabular}

on RFS was limited to patients aged $\geq 55$ years. However, to our knowledge, there are no previous studies analyzing the interaction effect between tumor size and age on the risk of BM from RCC patients. This study suggested that the higher risk of BM from RCC was observed in patients younger than 70 years old and the risk was even higher if his/her tumor size was $7 \mathrm{~cm}$ or larger. Besides, the impact of age was limited to patients with primary tumor size $\geq 7 \mathrm{~cm}$.

Our findings, if confirmed, have certain clinical implications. Those patients with a combination of age younger than 70 years old and tumors size $\geq 7 \mathrm{~cm}$ experience higher risk of developing brain metastasis. Clinicians should perform brain 
TABLE 3: Interaction test between age and tumor size on the risk of brain metastases from renal cell carcinoma.

\begin{tabular}{lcccc}
\hline Age (years) & Tumor size $(\mathrm{cm})$ & Crude & Model I & Model II \\
\hline$<70$ & $<7$ & Ref. & Ref. & Ref. \\
$\geq 70$ & $<7$ & $1.593(0.915,2.775), 0.1000$ & $1.369(0.780,2.402), 0.2740$ & $1.459(0.837,2.545), 0.1828$ \\
$<70$ & $\geq 7$ and $<10$ & $9.583(6.540,14.042),<0.0001$ & $3.787(2.499,5.740),<0.0001$ & $6.805(4.574,10.124),<0.001$ \\
$\geq 70$ & $\geq 7$ and $<10$ & $6.221(3.482,11.114),<0.0001$ & $2.569(1.391,4.742), 0.0026$ & $4.363(2.416,7.879),<0.001$ \\
$<70$ & $\geq 10$ & $14.990(10.336,21.740),<0.0001$ & $3.072(2.006,4.705),<0.0001$ & $8.555(5.709,12.821),<0.001$ \\
$\geq 70$ & $\geq 10$ & $8.252(4.320,15.761),<0.0001$ & $2.159(1.081,4.314), 0.0293$ & $4.868(2.503,9.470),<0.001$ \\
$P$ interaction & & 0.0231 & 0.1679 & 0.0480 \\
\hline
\end{tabular}

Model I was adjusted for bone metastasis, liver metastasis, and lung metastasis. Model II was adjusted for grade, N stage, marital status, race NEW, insurance, and Fuhrman grade.

computed tomography (CT) scans or magnetic resonance imaging (MRI) in patients younger than 70 years old for brain metastasis screening. If his/her tumor size was larger than $7 \mathrm{~cm}$, the need for brain CT or MRI screening was greatly increased.

Given that our study is large population-based, there were several unavoidable limitations that warrant consideration. Firstly, as a result of nonrandomized patient population, selection bias may occur in this study. Secondly, the comorbidities and performance status were not available in the SEER registry. Thirdly, the population of the SEER database sampled only in America may affect the generalizability of this study. Fourthly, theoretically, only if all patients underwent brain imaging, the true incidence of brain metastases could be calculated. However, there was no information on how BM were diagnosed in the SEER database, and we could not exclude those BM patients who were diagnosed by symptoms. Fifthly, the SEER database did not record detailed follow-up data on BM during the course of the disease. Hence, it is unable for us to evaluate how many patients developed BM during the course of the disease.

\section{Conclusion}

Both tumor size and age were independent risk factors for $\mathrm{BM}$ in patients with RCC. Patients with a larger tumor size and younger age might have the higher risk of developing $\mathrm{BM}$ at diagnosis of RCC. The impact of age on the risk of developing BM from RCC was limited to patients with tumor size $\geq 7 \mathrm{~cm}$. Age appeared not to impact the risk of BM development in patients with a smaller tumor size. Our findings need further investigation.

\section{Data Availability}

All data generated or analyzed during the present study was obtained from SEER program of the National Cancer Institute.

\section{Ethical Approval}

Since all information from the SEER database has been deidentified and no personal identifying information was used in this analysis, informed consent is not required for use of the SEER data.

\section{Conflicts of Interest}

The authors declare that the research was conducted in the absence of any commercial or financial relationships that could be construed as a potential conflict of interest.

\section{Authors' Contributions}

ZBK is responsible for data collection, data analysis, manuscript writing, and manuscript editing. SHC is responsible for data collection, data analysis, and manuscript writing. YHC is responsible for data collection, statistical analysis, and manuscript writing. YPW is responsible for data collection, manuscript writing, and manuscript editing. FL is responsible for statistical analysis. XYX is responsible for manuscript editing. QSZ is responsible for data analysis. $\mathrm{NX}$ is responsible for project development, protocol development, and manuscript editing. YW is responsible for project development, protocol development, data analysis, and manuscript editing. Zhi-Bin Ke, Shao-Hao Chen, Ye-Hui Chen, and Yu-Peng Wu contributed equally to this work.

\section{Acknowledgments}

This study was supported by the Fujian educational research programs for young and middle-aged teachers (Grant number: JT180187); Startup Fund for scientific research, Fujian Medical University (Grant number: 2017XQ1063); and Guiding Project of Science and Technology Department of Fujian Province (Grant number: 2019Y0018).

\section{References}

[1] M. Bianchi, M. Sun, C. Jeldres et al., "Distribution of metastatic sites in renal cell carcinoma: a population-based analysis," Annals of Oncology, vol. 23, no. 4, pp. 973-980, 2012.

[2] F. Bray, J. Ferlay, I. Soerjomataram, R. L. Siegel, L. A. Torre, and A. Jemal, "Global cancer statistics 2018: GLOBOCAN estimates of incidence and mortality worldwide for 36 cancers in 185 countries," CA: a Cancer Journal for Clinicians, vol. 68, no. 6, pp. 394-424, 2018.

[3] A. Rodriguez-Vida, T. E. Hutson, J. Bellmunt, and M. H. Strijbos, "New treatment options for metastatic renal cell carcinoma," ESMO Open, vol. 2, no. 2, article e000185, 2017.

[4] J. S. Barnholtz-Sloan, A. E. Sloan, F. G. Davis, F. D. Vigneau, P. Lai, and R. E. Sawaya, "Incidence proportions of brain 
metastases in patients diagnosed (1973 to 2001) in the Metropolitan Detroit Cancer Surveillance System," Journal of Clinical Oncology, vol. 22, no. 14, pp. 2865-2872, 2004.

[5] T. Chandrasekar, Z. Klaassen, H. Goldberg, G. S. Kulkarni, R. J. Hamilton, and N. E. Fleshner, "Metastatic renal cell carcinoma: Patterns and predictors of metastases-A contemporary population-based series," Urologic Oncology: Seminars and Original Investigations, vol. 35, no. 11, pp. 661.e7-661.e14, 2017.

[6] L. J. Schouten, J. Rutten, H. A. Huveneers, and A. Twijnstra, "Incidence of brain metastases in a cohort of patients with carcinoma of the breast, colon, kidney, and lung and melanoma," Cancer, vol. 94, no. 10, pp. 2698-2705, 2002.

[7] M. Sun, G. De Velasco, P. K. Brastianos et al., "The development of brain metastases in patients with renal cell carcinoma: epidemiologic trends, survival, and clinical risk factors using a population- based cohort," European Urology Focus, vol. 5, no. 3, pp. 474-481, 2018.

[8] O. Bennani, S. Derrey, O. Langlois et al., "Brain metastasis from renal cell carcinoma," Neurochirurgie, vol. 60, no. 1-2, pp. 12-16, 2014.

[9] U. M. Vogl, M. Bojic, W. Lamm et al., "Extracerebral metastases determine the outcome of patients with brain metastases from renal cell carcinoma," BMC Cancer, vol. 10, no. 1, article 480, 2010.

[10] Z. Ji, N. Bi, J. Wang et al., "Risk factors for brain metastases in locally advanced non-small cell lung cancer with definitive chest radiation," International Journal of Radiation Oncology, Biology, Physics, vol. 89, no. 2, pp. 330-337, 2014.

[11] E. Korkmaz Kirakli and O. Oztekin, "Is hippocampal avoidance during whole-brain radiotherapy risky for patients with small-cell lung cancer? Hippocampal metastasis rate and associated risk factors," Technology in Cancer Research \& Treatment, vol. 16, no. 6, pp. 1202-1208, 2017.

[12] X. Ma, H. Zhu, H. Guo et al., "Risk factors of brain metastasis during the course of EGFR-TKIs therapy for patients with EGFR-mutated advanced lung adenocarcinoma," Oncotarget, vol. 7, no. 49, pp. 81906-81917, 2016.

[13] L. E. Warren, H. Guo, M. M. Regan et al., "Inflammatory breast cancer and development of brain metastases: risk factors and outcomes," Breast Cancer Research and Treatment, vol. 151, no. 1, pp. 225-232, 2015.

[14] M. H. Hung, C. Y. Liu, C. Y. Shiau et al., "Effect of age and biological subtype on the risk and timing of brain metastasis in breast cancer patients," PLoS One, vol. 9, no. 2, article e89389, 2014.

[15] C. Maurer, L. Tulpin, M. Moreau et al., "Risk factors for the development of brain metastases in patients with HER2positive breast cancer," ESMO Open, vol. 3, no. 6, article e000440, 2018.

[16] J. Schovanek, V. Martucci, R. Wesley et al., "The size of the primary tumor and age at initial diagnosis are independent predictors of the metastatic behavior and survival of patients with SDHB-related pheochromocytoma and paraganglioma: a retrospective cohort study," BMC Cancer, vol. 14, no. 1, article 523, 2014.

[17] B. Tran, D. Roshan, E. Abraham et al., "The prognostic impact of tumor size in papillary thyroid carcinoma is modified by age," Thyroid, vol. 28, no. 8, pp. 991-996, 2018. 